\title{
A Study of Aerospace Engineering Student Professional Persistence
}

\section{Dr. Wm. Michael Butler, Virginia Tech}

Wm. Michael Butler is an Associate Professor of Practice in the Department of Engineering Education at Virginia Tech. He is a 24 year aerospace industry design professional with B.S. and M.S. in Aerospace Engineering from Virginia Tech and a PhD. in Engineering Education also from Virginia Tech. His engineering education research is focused on the use of design tools and live simulation in engineering design education as a means to better prepare students for industry. He is a Senior Member of AIAA and a member of ASEE. Michael is also a co-inventor on two patents relating to air vehicle design. 


\section{A Study of Aerospace Engineering Student Professional Persistence}

\section{Introduction}

Two issues facing the field of engineering are the pending retirement of the Baby Boom generation and the lack of diversity in the engineering workforce ${ }^{1,2}$. Both issues relate to a loss of knowledge in the field due the retirement of those with experience and the loss of alternative ideas and engineering potential by having a very homogenized group of engineering practitioners. In order to address these issues, there have been a number studies in engineering education exploring the area of academic persistence or the intention of a student to complete a degree in engineering as a way to increase the number of engineers and their diversity. Studies by Seymour and Hewitt (1997), Huang, Taddese and Walter (2000), and Adelman (1998) have explored various areas of academic persistence in science and engineering including the impacts of gender and ethnicity on persistence ${ }^{3,4,5}$. At the core of these academic persistence studies is the assumption that those who pursue and successfully complete a degree in science and engineering will in turn pursue a professional career in engineering or science. Is this a valid assumption and does it apply to aerospace engineering students?

\section{Literature Review}

In engineering education, the number of studies exploring professional persistence is limited. Studies by Amelink and Creamer (2010), Eris et al. (2010), and Lichtenstein et al. (2009) indicate that a number of factors impact professional persistence. Between these different studies it was found that ${ }^{1,6,7}$ :

1. respect from both peers and instructors was very important in keeping students satisfied with the engineering field and intending to work in the field for years in the future ${ }^{1}$.

2. the desire to pursue an engineering career increases throughout the education of the student in the case of persisters (those who graduated or were still working toward an engineering degree).

3. attaining an engineering degree did not equal a commitment to pursuing an engineering career and that the opinion about pursuing a career in engineering could be readily swayed in either direction depending on the experiences and interactions of the student. This includes co-op/ internship experiences where good experiences can lead to increased professional persistence and bad experiences can lead to students desiring not to want to work in the field ${ }^{7}$.

How do these general results for engineering relate to the particular field of aerospace engineering where there continues to be the need to bring new engineering talent into the field in order to maintain aerospace leadership in the United States as is discussed by the Committee on the National Aerospace Initiative $(2004)^{8}$ ? Do engineers in aerospace follow these same trends 
in persistence and do the aerospace programs training students today provide the necessary experiences to encourage students to desire to want to work in aerospace engineering as a career? How do factors such as age, gender, ethnicity, and co-op/ internship experience impact the professional persistence of aerospace engineering students? The following sections examine these questions through an analysis of the survey results of the Aerospace Student Attitudes survey.

\section{Research Problem}

This paper examines the following research questions:

1. What are the professional persistence characteristics of present day aerospace engineering students?

2. How does the aerospace engineering education experience influence student perception of aerospace engineering?

\section{Methods}

\section{Data Set}

The dataset used for this investigation contained the results of the 2009 administration of the web-based Survey of Aerospace Student Attitudes ${ }^{9}$, a cross-institution study administered by the Massachusetts Institute of Technology (MIT) to the population of aerospace engineering students in aerospace, aeronautical, or astronautical engineering programs across the United States. Principle investigator for the project was Dr. Annalisa Weigel of MIT. The research sought to "gain insights into what motivates students to study aerospace engineering, how their experiences influence their career choice, and what their perspectives are on a future career in or outside of the aerospace industry" with the aim of using the results to "identify reasons that students might not stay in the aerospace field, and to help formulate practices to hire and retain engineers" 9 .

\section{Participants}

The population of this study consisted of sophomores and seniors in aerospace engineering. The aim of such a split was to have representatives of the aerospace engineering population that were just beginning their undergraduate aerospace curriculum and those just completing their aerospace curriculum. In 2009, students from 22 different universities participated in this study. These institutions are listed in Table 1. 
Table 1

Aerospace Student Attitudes Survey Participating Institutions

\begin{tabular}{lll}
\hline Auburn University & Ohio State University & $\begin{array}{l}\text { University of } \\
\text { Maryland }\end{array}$ \\
$\begin{array}{l}\text { California Polytechnic State } \\
\text { University }\end{array}$ & Penn State University & University of Minnesota \\
George Washington University & Purdue University & University of Oklahoma \\
Georgia Institute of Technology & Syracuse University & Virginia Tech \\
Illinois Institute of Tech & Texas A\&M University & \\
Iowa State University & University of Alabama in & \\
Massachusetts Inst. of Tech. & Huntsville & \\
Mississippi State University & University of Arizona & \\
Naval Postgraduate School & Diego & \\
\hline
\end{tabular}

There were a total of 613 participants ( $80 \%$ male and $20 \%$ female). The respondents ranged in age from 17 to 27 years of age. The majority (greater than 74\%) of these respondents were United States citizens. Roughly $57 \%$ of the respondents identified themselves as White/Caucasian with the balance identifying themselves as races other than White/Caucasian. Roughly $27 \%$ of the respondents had an internship or co-op experience ${ }^{9}$.

\section{Measures}

The Aerospace Student Attitudes Survey consists of five constructs. These constructs are: (1) motivating factors for initial interest in the aerospace industry, (2) influence of college experiences on student choice of the aerospace industry, (3) career expectations and desired job attributes, (4) student perceptions of the aerospace industry and of alternative careers, and (5) demographics 9 . This paper examines those constructs relating to professional persistence of the students and how that persistence varies based upon a variety of independent and control variables detailed in the following subsections.

\section{Dependent variables}

See Yourself Entering the Aerospace Industry upon Graduation (WILLENTERAERO). This variable measures the respondents' current thinking on whether or not the respondent will enter the aerospace industry upon completion of undergraduate or graduate education.

College/University Experience Gave a Positive/Negative Impression of the Aerospace Industry (POSNEGEXP). This variable measures the respondents' attitudes about how the college or 
university experience to date have given the respondent an overall positive or negative impression of the aerospace industry.

Likelihood of Staying in an Aerospace-Related Job for Whole Career (POSSTAYAERO). This variable measures the respondents' current thinking on how likely they were to stay in an aerospace-related job for the duration of their careers.

Influence on the Desire to Work in Aerospace. This variable describes the respondents' view on how each of the following items has influenced the respondent's desire to work in aerospace: engineering classes, non-engineering classes, hands-on experience, summer job or internship or co-op experience, on-campus research opportunities, membership in an aerospace -related organization, industry speakers that visit the campus, career fairs, faculty, non-faculty mentor, and other.

\section{Independent variables}

Gender. This variable describes the respondent's sex.

Age. This continuous variable describes the respondent's age. Respondents input this value into the survey.

Ethnicity/Race. This variable describes the respondent's ethnicity or race. Respondents were provided the options of White, Black/African American, Hispanic/Latino, Asian or Pacific Islander, American Indian or Alaskan Native, and Other where the respondent had to specify.

Family/Friends are Engineers. This variable is the number of family members or close family friends of the respondent that are engineers.

Age of First Interest in Aerospace. This variable is the age at which the respondent first became interested in aerospace. Respondents typed this response in the survey.

\section{Control variables}

Co-op or Summer Internship Experience. This variable indicates whether or not the respondent had an internship or co-op experience in the aerospace industry.

\section{Analysis}

Multivariate analysis was conducted to examine the relationships between the independent and control variables age, gender, ethnicity/race, initial aerospace interest, family and friend influences, and co-op experience with the dependent variables characterizing the respondents' views on the aerospace industry and desire to work in the field. Model 1 examines the dependent variable WILLENTERAERO, which relate to whether or not the respondent will likely enter the aerospace industry. Model 2 examines the dependent variable POSSTAYAERO, which relates to whether respondents are likely stay in an aerospace related job for the duration 
of their careers. Model 3 examines the positive or negative view of the respondent towards aerospace based upon the collegiate experience thus far. Each of these models is analyzed against the aforementioned independent and control variables using logistic regression given the binary nature of the responses. Models 4 through 13 examine the influence of engineering classes, non-engineering classes, hands-on experience, internship or co-op experience, oncampus research opportunities, membership in an aerospace-related organization, industry speakers that visit the campus, career fairs, faculty, non-faculty mentor, and other, respectively, on the desire to work in aerospace against the aforementioned list of independent and control variables. Given the Likert scale ordered response options available to the respondents in Models 4 through 13, an ordinal logistic regression was utilized. For this particular analysis, the variables were recoded to reverse the order of respondent options such that Strong positive influence is recoded as 4 , positive influence is recoded as 3, negative influence is recoded as 2 , and strong negative influence is recoded as 1 . Not applicable was coded as missing. The level of confidence that was used to determine statistical significance in the relationship between variables for all models was $95 \%$.

\section{Results}

Table 2

Descriptive Statistics for the Survey of Aerospace Student Attitudes

\begin{tabular}{lcccc} 
Variable & $\mathrm{N}$ & $\mathrm{M}$ & $\mathrm{SD}$ & Range \\
\hline Dependent Variables & & & & \\
See Entering Aerospace Industry & 434 & 0.871 & 0.336 & $0-1$ \\
Intend to Stay in Aerospace-Related jobs & 479 & 0.789 & 0.408 & $0-1$ \\
Collegiate Experience Pos/Neg View of Aerospace & 512 & 0.877 & 0.336 & $0-1$ \\
Influence related variables & & & & \\
$\quad$ Aerospace Organizations & 276 & 1.837 & 0.525 & $1-4$ \\
Career Fairs & 376 & 2.077 & 0.728 & $1-4$ \\
Engineering Classes & 502 & 1.883 & 0.764 & $1-4$ \\
Non-Engineering Classes & 355 & 2.051 & 0.618 & $1-4$ \\
Faculty & 459 & 1.874 & 0.678 & $1-4$ \\
Non-Faculty & 216 & 1.852 & 0.584 & $1-4$ \\
Hands-on Experience & 442 & 1.486 & 0.599 & $1-4$ \\
Industry Speakers & 348 & 1.819 & 0.502 & $1-4$ \\
On-campus Research & 215 & 1.749 & 0.657 & $1-4$ \\
Internships/Summer Jobs & 247 & 1.644 & 0.756 & $1-4$ \\
Other & 34 & 1.853 & 0.584 & $1-4$ \\
Independent Variables & & & & 0.49 \\
Age & 478 & 21.05 & 1.891 & $17-27$ \\
Gender & 480 & 0.206 & 0.405 & $0-1$ \\
Ethnicity & 476 & 0.264 & 0.441 & $0-1$ \\
Family/Friends Engineers. & 561 & 0.597 & 0.491 & $0-1$ \\
First Interest in Aerospace & 551 & 0.080 & 0.271 & $0-1$ \\
Co-op Internship & 520 & 0.325 & 0.469 & $0-1$ \\
\hline
\end{tabular}


Table 2 shows the means and standard deviations for the variables used in this study. Since all respondents did not answer all items, the number of responses for each item varies and the statistics reflect those varying sample sizes. From this data we can see that the average age of the respondents is just over 21 years old. The majority of the respondents are male with roughly $20 \%$ of the respondents being female. Twenty-six percent of the respondents are races other than White. Sixty percent of the respondents have family or close family friends that are engineers. Only $8 \%$ of the respondents had their first interest in aerospace occur after high school. Of the respondents, only $32.5 \%$ of them had a co-op or internship experience.

In the case of the dependent variables, we see that the mean responses are all positive (all greater than 0.5 with 1.0 being yes) to the questions of whether or not the students saw themselves going into the aerospace industry, intending to stay in aerospace related jobs for their careers, and had a university experience that gave them a positive view of the aerospace industry. Relative to the set of dependent variables that influence the student desire to work in aerospace engineering, we see that all variables have a value less than two indicating that the mean response falls between positive influence (value of 2) and strong positive influence (value of 1). (Note for the ordered logistic analysis, the response options discussed here were reverse coded with strong positive influence as 4 and strong negative influence as 1.) The only items with means greater than two are career fairs and non-engineering classes where these two items are less than 0.1 over the value of 2.0 thus making them still close to positive influences.

Table 3

Logistic Regression Results for the Variables WILLENTERAERO (Model 1), POSSTAYAERO (Model 2), and POSNEGEXP (Model 3)

\begin{tabular}{|c|c|c|c|c|c|c|}
\hline \multirow[b]{2}{*}{ Variable } & \multicolumn{2}{|c|}{$\underline{\text { Model } 1}$} & \multicolumn{2}{|c|}{$\underline{\text { Model } 2}$} & \multicolumn{2}{|c|}{$\underline{\text { Model } 3}$} \\
\hline & $\mathrm{b}$ & $\operatorname{Exp}(b)$ & $\mathrm{b}$ & $\operatorname{Exp}(b)$ & b & $\operatorname{Exp}(b)$ \\
\hline \multirow[t]{2}{*}{ Age } & $-0.216 * *$ & 0.806 & $-0.116 \dagger$ & 0.891 & $-0.155^{*}$ & 0.857 \\
\hline & $(0.077)$ & & $(0.062)$ & & $(0.075)$ & \\
\hline \multirow[t]{2}{*}{ Gender } & -0.080 & 0.923 & 0.218 & 1.243 & -0.410 & 0.664 \\
\hline & $(0.386)$ & & $(0.307)$ & & $(0.342)$ & \\
\hline \multirow[t]{2}{*}{ Ethnicity } & -0.108 & 0.898 & 0.169 & 1.185 & 0.615 & 1.849 \\
\hline & $(0.346)$ & & $(0.275)$ & & $(0.388)$ & \\
\hline \multirow[t]{2}{*}{ Family/Friends Engineers } & 0.109 & 1.115 & 0.255 & 1.291 & 0.392 & 1.480 \\
\hline & $(0.309)$ & & $(0.237)$ & & $(0.296)$ & \\
\hline \multirow[t]{2}{*}{ First Interest in Aerospace } & $1.887 \dagger$ & 6.602 & 0.280 & 1.323 & -0.128 & 0.880 \\
\hline & $(1.063)$ & & $(0.483)$ & & $(0.535)$ & \\
\hline \multirow[t]{2}{*}{ Co-op Internship } & $1.023 * *$ & 2.780 & -0.063 & 0.939 & 0.008 & 1.008 \\
\hline & $(0.376)$ & & $(0.249)$ & & $(0.311)$ & \\
\hline Constant & $6.134 * *$ & & $3.577 * *$ & & $5.040 * *$ & \\
\hline $\mathrm{N}$ & 407 & & 452 & & 451 & \\
\hline
\end{tabular}


Table 3 shows the results of the binary logistic regression the variables WILLENTERAERO, POSNEGEXP, and POSSTAYAERO regressed against age, gender, ethnicity, if the respondent has family and friends who are engineers, if the respondent first became interested in aerospace before or during college and whether or not the respondent has had a co-op or internship experience. Not all respondents answered all questions and thus the number of respondents per question does vary and is listed in the Table 3 . In the case of Model 1 dealing with the question of whether or not the respondent will enter the aerospace industry upon graduation, only the variables of age and co-op experience were statistically significant to the 0.01 level while the variable first interest in aerospace is only significant if we use a 0.1 significance level. All other variables under consideration do not have statistically significant relationships. The variable age has a negative logistic coefficient indicating that as the age of the respondent increases, the respondent is less likely to agree with the statement that the respondent will most likely enter the aerospace industry upon graduation. In particular the odds ratio indicates that the respondent is about $19 \%$ less likely to agree with the statement for every unit increase in age. The variable co-op/internship has a positive logistic coefficient indicating that if the respondent had a co-op or internship experience, the respondent is more likely to agree with the statement that the respondent will most likely enter the aerospace industry upon graduation. In particular the odds ratio indicates that the co-op/ internship respondent is nearly three times more likely to agree with the statement than one without the co-op/internship experience. The Nagelkerke pseudo R-Square for this model indicates that roughly $7.7 \%$ of the variability in the odds of agreeing with the statement that the respondent will likely enter aerospace industry can be accounted for by the predictors of age, gender, ethnicity, having family or family friends that are engineers, having an interest in aerospace start after high school, and having had a co-op or internship.

For the case of Model 2 dealing with the question of whether or not the respondent will stay in aerospace related jobs for the duration of the respondents' career, none of the variables under consideration have statistically significant relationships to the 0.05 level of significance or less. Only the variable age has a statistically significance relationship to the 0.1 level. With Model 3 dealing with the question of whether or not the college or university experience has given the respondent a positive impression of aerospace, only the variable age has a statistically significant relationship to the 0.05 level of significance. All other variables under consideration do not have statistically significant relationships. The variable age has a negative logistic coefficient indicating that as the age of the respondent increases, the respondent is less likely to agree with the statement that the college or university experience has given the respondent a positive impression of aerospace. In particular the odds ratio indicates that the respondent is about $14 \%$ less likely to agree with the statement for every unit increase in age. The Nagelkerke pseudo R-Square for Model 3 indicates that roughly $4.8 \%$ of the variability in the odds of agreeing with the statement that the respondent will stay in an aerospace-related job for the duration of the respondent's career can be accounted for by the predictors of age, gender, 
ethnicity, having family or family friends that are engineers, having an interest in aerospace start after high school, and having had a co-op or internship.

Table 4 shows the results of the ordinal logistic regression with the variables dealing with the influence of various items on the respondent's view of aerospace regressed against age, gender, ethnicity, if the respondent has family and friends who are engineers, if the respondent first became interested in aerospace before or during college and whether or not the respondent has had a co-op or internship experience. A model for the influence of other is not included in Table 4 since the sample size was too low (only 29 responses for this item) to run a valid ordinal regression model. Response options were reverse coded for this analysis versus that presented in the descriptives data. Each of the presented models uses the "strong positive influence" option as the reference category for the ordinal regression. The predictors used in each of the following models are age, gender, ethnicity, having family or family friends that are engineers, having an interest in aerospace start after high school, and having had a co-op or internship.

Table 4

Ordinal Regression for the Influences on Respondents'Attitudes Toward Aerospace [Engineering Classes (Model 4), Non-engineering Classes (Model 5), Hands-on Experience (Model 6), Summer job or Internship Experience (Model 7), On-campus Research (Model 8), Aerospace-related Organization Membership (Model 9), Industry Speakers (Model 10), Career Fairs (Model 11), Faculty (Model 12) Nonfaculty Mentor (Model 13)]

\begin{tabular}{|c|c|c|c|c|c|c|c|c|c|c|}
\hline Variable & $\frac{\text { Model } 4}{\mathrm{~b}}$ & $\frac{\text { Model } 5}{\mathrm{~b}}$ & $\frac{\text { Model } 6}{\mathrm{~b}}$ & $\frac{\text { Model } 7}{b}$ & $\frac{\text { Model } 8}{\mathrm{~b}} \frac{\mathrm{N}}{\mathrm{N}}$ & $\frac{\text { Model } 9}{\mathrm{~b}}$ & $\frac{\text { Model 10 }}{b}$ & $\frac{\text { Model 11 }}{\mathrm{b}}$ & $\frac{\text { Model 12 }}{\mathrm{b}} \mathrm{N}$ & $\frac{\text { Model } 13}{\mathrm{~b}}$ \\
\hline Age & $\begin{array}{c}-0.201 * * \\
(0.051)\end{array}$ & $\begin{array}{l}-0.073 \\
(0.070)\end{array}$ & $\begin{array}{l}-0.013 \\
(0.059)\end{array}$ & $\begin{array}{l}-0.067 \\
(0.082)\end{array}$ & $\begin{array}{l}-0.207^{*} \\
(0.095)\end{array}$ & $\begin{array}{l}-0.131 \\
(0.085)\end{array}$ & $\begin{array}{l}-0.060 \\
(0.071)\end{array}$ & $\begin{array}{l}-0.096 \\
(0.064)\end{array}$ & $\begin{array}{l}-0.049 \\
(0.055)\end{array}$ & $\begin{array}{l}-0.043 \\
(0.086)\end{array}$ \\
\hline Gender & $\begin{array}{l}-0.087 \\
(0.230)\end{array}$ & $\begin{array}{c}0.197 \\
(0.306)\end{array}$ & $\begin{array}{c}0.704 * * \\
(0.264)\end{array}$ & $\begin{array}{l}0.812 * \\
(0.345)\end{array}$ & $\begin{array}{c}0.387 \\
(0.367)\end{array}$ & $\begin{array}{l}0.714 * \\
(0.354)\end{array}$ & $\begin{array}{c}0.331 \\
(0.326)\end{array}$ & $\begin{array}{c}0.254 \\
(0.281)\end{array}$ & $\begin{array}{c}0.025 \\
(0.248)\end{array}$ & $\begin{array}{c}0.380 \\
(0.384)\end{array}$ \\
\hline Ethnicity & $\begin{array}{c}0.267 \\
(0.211)\end{array}$ & $\begin{array}{l}-0.029 \\
(0.275)\end{array}$ & $\begin{array}{c}0.152 \\
(0.232)\end{array}$ & $\begin{array}{c}0.067 \\
(0.313)\end{array}$ & $\begin{array}{c}0.260 \\
(0.343)\end{array}$ & $\begin{array}{c}0.439 \\
(0.329)\end{array}$ & $\begin{array}{l}-0.167 \\
(0.296)\end{array}$ & $\begin{array}{l}-0.247 \\
(0.247)\end{array}$ & $\begin{array}{l}0.489^{*} \\
(0.222)\end{array}$ & $\begin{array}{c}0.022 \\
(0.346)\end{array}$ \\
\hline Family/Friends Engineers & $\begin{array}{l}-0.011 \\
(0.189)\end{array}$ & $\begin{array}{l}-0.169 \\
(0.252)\end{array}$ & $\begin{array}{l}0.388 \dagger \\
(0.209)\end{array}$ & $\begin{array}{l}0.305 \\
(.279)\end{array}$ & $\begin{array}{c}0.027 \\
(0.305)\end{array}$ & $\begin{array}{c}0.150 \\
(0.308)\end{array}$ & $\begin{array}{l}-0.203 \\
(0.264)\end{array}$ & $\begin{array}{l}0.593 * \\
(0.232)\end{array}$ & $\begin{array}{c}0.155 \\
(0.202)\end{array}$ & $\begin{array}{c}0.345 \\
(0.333)\end{array}$ \\
\hline First Interest in Aerospace & $\begin{array}{l}0.686 \dagger \\
(0.359)\end{array}$ & $\begin{array}{c}0.693 \\
(0.485)\end{array}$ & $\begin{array}{l}-0.539 \\
(0.408)\end{array}$ & $\begin{array}{l}-0.266 \\
(0.541)\end{array}$ & $\begin{array}{l}-0.747 \\
(0.753)\end{array}$ & $\begin{array}{c}-1.177 \dagger \\
(0.645)\end{array}$ & $\begin{array}{l}-0.797 \\
(0.629)\end{array}$ & $\begin{array}{l}-0.532 \\
(0.453)\end{array}$ & $\begin{array}{l}-0.172 \\
(0.384)\end{array}$ & $\begin{array}{c}0.712 \\
(0.597)\end{array}$ \\
\hline Co-op Internship & $\begin{array}{c}0.034 \\
(0.199)\end{array}$ & $\begin{array}{l}-0.058 \\
(0.269)\end{array}$ & $\begin{array}{l}-0.045 \\
(0.215)\end{array}$ & $\begin{array}{l}1.308^{* *} \\
(0.303)\end{array}$ & $\begin{array}{c}0.032 \\
(0.307)\end{array}$ & $\begin{array}{l}-0.539 \\
(0.329)\end{array}$ & $\begin{array}{c}-0.470 \dagger \\
(0.285)\end{array}$ & $\begin{array}{c}0.360 \\
(0.236)\end{array}$ & $\begin{array}{c}-0.083 \\
(0.213)\end{array}$ & $\begin{array}{c}0.371 \\
(0.335)\end{array}$ \\
\hline Constant & & & & & & & & & & \\
\hline$[1.00=$ Strong Neg. Influence $]$ & $-7.304 * *$ & $5.518 * *$ & $-4.830 * *$ & $-3.529 \dagger$ & $-8.415 * *$ & $*-7.634 * *$ & ----- & $-4.868 * *$ & $-4.646 * *$ & $-4.985^{*}$ \\
\hline [2.00=Neg. Influence] & $-5.839 * *$ & $-3.209^{*}$ & $-3.262 *$ & -2.660 & $-6.723 * *$ & $*-5.881 * *$ & $-4.937 * *$ & $-2.969^{*}$ & $-2.729^{*}$ & -2.817 \\
\hline [3.00=Pos. Influence $]$ & $-3.299 * *$ & 0.270 & -0.171 & -0.120 & $-3.606^{*}$ & -1.312 & -0.398 & -0.049 & 0.145 & 0.773 \\
\hline Pseudo R -Square & 0.054 & 0.016 & 0.040 & 0.129 & 0.055 & 0.083 & 0.032 & 0.056 & 0.021 & 0.030 \\
\hline $\mathrm{N}$ & 440 & 308 & 390 & 216 & 181 & 237 & 303 & 325 & 403 & 185 \\
\hline
\end{tabular}

In Model 4 the issue of whether engineering classes have a positive or negative influence on respondents' desire to work in aerospace is examined. We see that only the variable age has a statistically significant relationship at the less than 0.01 level. The logistic coefficient with this variable is negative, thus, in this case, as the age of the respondent increases, the respondent is less likely to agree with the statement that engineering classes have a strong positive influence 
on the respondent's desire to work in aerospace than the statements that engineering classes have a positive influence, negative influence, or strong negative influence. All other variables in Model 4 do have not statistically significant relationships to the less than 0.05 significance level. Only the variable having a first interest in aerospace after high school has significance to the less than 0.1 level. The Nagelkerke pseudo R-Square for Model 4 indicates that roughly $5.4 \%$ of the variability in the odds of agreeing with the statement that engineering classes have a strong positive influence on the desire to work in aerospace can be accounted for by the predictors.

In Model 5 the issue of whether non-engineering classes have a positive or negative influence on respondents' desire to work in aerospace is examined. None of the variables in Model 5 have a statistically significant relationship to the less than 0.05 significance level.

In Model 6 the issue of whether hands-on experiences have a positive or negative influence on respondents' desire to work in aerospace is examined. We see that only the variable gender has a statistically significant relationship at the less than 0.01 level. The logistic coefficient for this variable is positive thus females are more likely than males to agree with the statement that hands-on experiences have a strong positive influence on the respondent's desire to work in aerospace than the statements that hands-on experiences have a positive influence, negative influence, or strong negative influence. All other variables in Model 6 do have not statistically significant relationships to the less than 0.05 significance level. Only the variable having family or close family friends who are engineers has significance to the less than 0.1 level. The Nagelkerke pseudo R-Square for Model 6 indicates that roughly $4.0 \%$ of the variability in the odds of agreeing with the statement that hands-on experiences have a strong positive influence on the desire to work in aerospace can be accounted for by the predictors.

In Model 7 the issue of whether summer job or co-op/internship experiences have a positive or negative influence on respondents' desire to work in aerospace is explored. We see that the variables gender and co-op/intern experience have statistically significant relationships at the less than 0.05 and 0.01 levels, respectively. The logistic coefficient for gender is positive thus females are more likely than males to agree with the statement that summer jobs or coop/internship experiences have a strong positive influence on the respondent's desire to work in aerospace than the statements that summer jobs or co-op/internship experiences have a positive influence, negative influence, or strong negative influence. The logistic coefficient for coop/internship experience is positive thus respondents with co-op/internship experience are more likely than those without co-op/internship experience to agree with the statement that summer jobs or co-op/internship experiences have a strong positive influence on the respondent's desire to work in aerospace than the statements that summer jobs or co-op/internship experiences have a positive influence, negative influence, or strong negative influence. All other variables in Model 7 do have not statistically significant relationships to the less than 0.05 significance level. The Nagelkerke pseudo R-Square for Model 7 indicates that roughly $13 \%$ of the variability in the odds of agreeing with the statement that summer jobs or co-op/internship experiences have a 
strong positive influence on the desire to work in aerospace can be accounted for by the predictors.

Model 8 examines whether on-campus research experiences have a positive or negative influence on respondents' desire to work in aerospace. We see that only the variable age has a statistically significant relationship at the less than 0.05 level. The logistic coefficient with this variable is negative thus as the age of the respondent increases, the respondent is less likely to agree with the statement that on-campus research experiences have a strong positive influence on the respondent's desire to work in aerospace than the statements that on-campus research experiences have a positive influence, negative influence, or strong negative influence. All other variables in Model 8 do have not statistically significant relationships to the less than 0.05 significance level. The Nagelkerke pseudo R-Square for Model 8 indicates that roughly 5.5\% of the variability in the odds of agreeing with the statement that on-campus research experiences have a strong positive influence on the desire to work in aerospace can be accounted for by the predictors.

In Model 9 the issue of whether aerospace-related organizations have a positive or negative influence on respondents' desire to work in aerospace is examined. We see that only the variable gender has a statistically significant relationship at the less than 0.05 level. The logistic coefficient for this variable is positive thus females are more likely than males to agree with the statement that aerospace-related organizations have a strong positive influence on the respondent's desire to work in aerospace than the statements that aerospace-related organizations have a positive influence, negative influence, or strong negative influence. All other variables in Model 9 do have not statistically significant relationships to the less than 0.05 significance level. Only the variable having an interest in aerospace start after high school has significance to the less than 0.1 level. The Nagelkerke pseudo R-Square for Model 9 indicates that roughly $8.3 \%$ of the variability in the odds of agreeing with the statement that aerospace-related organizations have a strong positive influence on the desire to work in aerospace can be accounted for by the predictors.

In Model 10 the issue of whether industry speakers have a positive or negative influence on respondents' desire to work in aerospace is analyzed. The intercept for " $1.00=$ strong negative influence" contained too few cases to be calculated for this model. None of the variables in Model10 have a statistically significant relationship to the less than 0.05 significance level though having co-op/internship experience is a statistically significant relationship to the less than 0.1 significance level.

In Model 11 the issue of whether career fairs have a positive or negative influence on respondents' desire to work in aerospace is explored. We see that only the variable having family or close family friends that are engineers has a statistically significant relationship at the less than 0.05 level. The logistic coefficient for this variable is positive thus those who have family or close family friends that are engineers are more likely than those who do not have 
family or close family friends that are engineers to agree with the statement that career fairs have a strong positive influence on the respondent's desire to work in aerospace than the statements that career fairs have a positive influence, negative influence, or strong negative influence. All other variables in Model 11 do have not statistically significant relationships to the less than 0.05 significance level. The Nagelkerke pseudo R-Square for Model 11 indicates that roughly 5.6\% of the variability in the odds of agreeing with the statement that career fairs have a strong positive influence on the desire to work in aerospace can be accounted for by the predictors.

In Model 12 the issue of whether faculty has a positive or negative influence on respondents' desire to work in aerospace is examined. We see that only the variable ethnicity has a statistically significant relationship at the less than 0.05 level. The logistic coefficient for this variable is positive thus those respondents who are not White/Caucasian are more likely than those who are White/Caucasian to agree with the statement that faculty has a strong positive influence on the respondent's desire to work in aerospace than the statements that faculty has a positive influence, negative influence, or strong negative influence. All other variables in Model 12 do have not statistically significant relationships to the less than 0.05 significance level. The Nagelkerke pseudo R-Square for Model 12 indicates that roughly $2.1 \%$ of the variability in the odds of agreeing with the statement that faculty has a strong positive influence on the desire to work in aerospace can be accounted for by the predictors.

Finally in Model 13 the issue of whether non-faculty has a positive or negative influence on respondents' desire to work in aerospace is analyzed. None of the variables in Model 13 have a statistically significant relationship to the less than 0.05 significance level.

\section{Discussion}

The results of these analyses provide interesting insight into the thinking and attitudes of today's aerospace engineering students. These attitudes form the basis for the professional persistence attributes of these students at this time and how they view the field of aerospace engineering. The pending need for aerospace engineers to fill the slots vacated by those retiring in the coming years as the Baby Boom generation retires, necessitates that engineering schools produce not only engineering graduates but graduates that seek to enter the aerospace field and become practicing engineers.

The descriptive statistics of this study tell a story of where nearly $90 \%$ of the respondents see themselves entering the aerospace engineering field and nearly $80 \%$ of the respondents see themselves staying in aerospace related jobs for the duration of their careers. On top of that we see that nearly $90 \%$ of the respondents feel that the university or collegiate experience has helped to give the students an overall positive impression of the aerospace industry. This is good news for the profession but does it tell the whole story? Further statistical analysis of the data reveals a more complex view of the aerospace engineering is held by the students. Some of the findings are expected while others are little surprising. 
Looking at the logistic regression results, we can start to draw a more complete picture of the aerospace engineering respondents. We find that the co-op / internship experience does have a positive impact on the aerospace engineering students where students who do co-op or intern are roughly three times more likely to say that they plan on entering the aerospace engineering field. This somewhat begs the question of whether those co-op students are more likely to say that they are going into the aerospace field because they have secured a job with the company that they had the co-op or internship experience with. Additional data provided in the Aerospace Student Attitudes Survey reveals that of the co-op/intern students, only $41.7 \%$ of those students accepted jobs at the companies with which they had had a co-op/internship experience. The balance, $58.3 \%$ of the respondents, accepted jobs at companies other than those with which they had experience. This appears to indicate that the work experience itself plays a larger role than the fact that a student may have worked at Company X and created an inroad that led to a positive post-graduation job outlook and positive attitude of the field. When considering the findings of Lichtenstein et al (2009) where the impact of the co-op experience on professional experience can be either a positive or a negative, in turn keeping people in the field or driving them away, it appears that for the respondents of this survey, the former holds true ${ }^{7}$.

Whereas the co-op/internship experience provides promising results for positive professional persistence we find that age tends to have a negative influence on the students view of aerospace engineering and the prospects of a career in the field. The results show that as the age of the respondents increases, the desire to enter the aerospace industry actually decreases and the potential for feeling that the college or university experience creating a negative impression of the aerospace industry actually increases. Though not statistically significant to the $95 \%$ confidence level, we also see that these same negative trends hold when it comes to belief that the respondent will most likely stay in an aerospace-related job. Given that the target population for the study consisted of sophomores and seniors, it is believed that a shift occurs in the students as they move from the level where they are just beginning their experiences in aerospace to when they are just about to finish their initial formal training in the field and begin their professional lives. Whereas the sophomores may be very optimistic and excited about the possibilities of the field that they are just beginning to learn about, the seniors are tempered by the experience and rigor required to complete an engineering degree such as aerospace. The PIE study results by Eris et al (2010) note that the participants found the junior year of an engineering program to be especially challenging ${ }^{6}$. This impacts student perception of their own skills which can in turn impact their perception of the field and how they see themselves being a part of that field. Depending on when during the senior year the students took the survey, this negative influence of the junior year could have an impact on the students' responses to this item. The review of the ordinal regression results shows a consistent trend for age and is discussed later in this section.

None of the independent variables have a statistically significant relationship with the question concerning the desire to stay in an aerospace-related field for the duration of a respondent's career. This result is also consistent with the results of Lichtenstein et al (2009) 
which show that the present generation of engineers in school views themselves as having multiple careers and engineering may just be one of them ${ }^{7}$. They view having an engineering degree as a good starting point in preparation for a variety of other pursuits. It is possible here that the aerospace students hold a similar career view and thus the variables of age, gender, ethnicity, co-op experience etc. are not showing up as statistically significant results. Interviews with some of the respondents may provide further insight in this area.

The ordinal logistic analysis results also provide interesting insights into how individual items influence the respondent's desire to work in the aerospace field. Here again we see the variable age having a statistically significant impact. The older students tend to feel that engineering classes and on-campus research strongly do not influence them to want to work in aerospace. No other items that tend to be campus based including aerospace related organizations, career fairs, faculty, non-faculty and hands on experiences show a statistically significant relationship with age. This result is consistent with the earlier finding and it appears to some degree that the engineering courses themselves (noted earlier as being challenging during the junior year) and on-campus research are contributors to the older students not being as willing to say that they will enter the aerospace field as a career.

When it comes to gender, we see that aerospace related organizations, hands-on experiences, and summer internship/co-op experiences all have more positive effects on female respondents than male respondents. Thus it appears that efforts to increase experiences such as internships, hands-on work, and organizations such as the American Institute of Aeronautics and Astronautics (AIAA) do pay off with increased desire to work in the aerospace among the female respondents. We also see that faculty has a statistically significant relationship to respondents who are non-White/Caucasian versus White/Caucasian in creating a positive influence on the students that encourages them to want to pursue a career in aerospace. Continued support by faculty for these underrepresented students is also encouraging and is a partial solution to the professional persistence problem that can be acted upon by continuing and growing support for the instructors of the aerospace students.

Those respondents who have family and close family friends who are engineers only appear to have a statistically significant relationship to the $95 \%$ confidence level when it comes to career fairs. It is believed here that the fact that the respondent knows an engineer fairly well probably plays an important part in that respondent being able to identify with aerospace engineers at career fairs versus other non-engineering fields that may be represented at such events. Though only statistically significant to the 0.1 level, we also see that those with family and close family friends who are engineers are also positively influenced by hands on experiences. It is thought here that those respondents may have heard stories about the various engineering experiences of the family member or close friend and may have been encouraged by them and the hands-on experience provided an opportunity for the respondents to have their own similar engineering experiences. 
Students who became interested in aerospace after high school (i.e. during college) do not have any statistically significant relationships to the 0.05 level but do have two to the 0.1 level for the items of aerospace related organizations and engineering classes. The students here became first interested in aerospace after they started college and the fact that engineering courses and aerospace related organizations have a positive influence on these students to want to work in aerospace is consistent with someone becoming interested in the field through experiences gained while at university versus other non-academic settings.

Co-op students have a strong statistically significant relationship with co-op/internships indicating that these experiences were positive for the students and reinforce a desire to work in the field. Though only statistically significant to the 0.1 level or less, the co-op/intern students also show a relationship with industry speakers that come to the campus. Again being visited by someone in the field that is representative of the positive co-op/intern experience had by the respondent probably reinforces their beliefs in pursuing an aerospace career. The co-op/intern can identify with and relate to the speaker.

\section{Limitations}

The presented analyses only cover the 2009 results of the Aerospace Student Attitudes Survey. Further analysis of the other administrations of the survey such as the 2010 results would be necessary to see if findings from the 2009 data form trends over time. An increased sample size beyond the nearly 600 respondents of the 2009 survey will also increase the generalizability of the results.

\section{Conclusions}

The results of the Aerospace Student Attitudes Survey indicate that most aerospace engineering students do plan to enter the field thus showing positive professional persistence. Students who experience the professional life of an aerospace engineer through co-op and internship experiences are encouraged by the experience and it appears to strengthen their desire to enter the field. Co-op/internship experiences and faculty also have a positive influence on underrepresented groups in aerospace engineering influencing these groups to desire to enter the field. Though these results are promising for the future of aerospace engineering, the study also shows that aerospace engineering students are finding that the engineering courses themselves are actually a negative influence on their desire to enter the aerospace industry as the students progress from sophomore year to senior year. This may be simply due to the gradual increase in difficulty of courses as students progress through an engineering program or it could be a hint of changes that may need to be made so that the students have a positive association between the training to become an aerospace engineer and the positive work experiences they have in the field as practicing engineers. 


\section{Bibliography}

1. Amelink, C. T., \& Creamer, E. G. (2010). Gender differences in elements of the undergraduate experience that influence satisfaction with the engineering major and the intent to pursue engineering as a career.

Journal of Engineering Education, 99(1), 81-92.

2. Levine, L. (2008). CRS report for congress: Retiring baby-boomers = a labor shortage? Washington D.C.: Congressional Research Service.

3. Seymour, E., \& Hewitt, N. M. (1997). Talking about leaving: Why undergraduate engineers leave the sciences. Boulder, CO: Westview Press.

4. Huang, G., Taddese, N., \& Walter, E. (2000). Entry and persistence of women and minorities in college science and engineering education. Washington, D.C.: U.S. Department of Education.

5. Adelman, C. (1998). Women and men of the engineering path: A model for analyses of undergraduate careers. Washington, DC: U.S. Department of Education.

6. Eris, O., Chachra, D., Chen, H. L., Sheppard, S. D., Ludlow, L., Rosca, C., . . Toye, G. (2010). Outcomes of a longitudinal administration of the persistence in engineering survey. Journal of Engineering Education, 99(4), 371-395.

7. Lichtenstein, G., Loshbaugh, H. G., Claar, B., Chen, H. L., Jackson, K., \& Sheppard, S. D. (2009). An engineering major does not (necessarily) an engineer make: Career decision making among undergraduate engineering majors. Journal of Engineering Education, 98(3), 227-234.

8. Committee on the National Aerospace Initiative, Air Force Science and Technology Board Division on Engineering and Physical Sciences. (2004). Evaluation of the National Aerospace Initiative. Washington, DC: National Academies Press.

9. Weigel, A. (2010). "Survey of aerospace student attitudes." Retrieved February 20, 2011, from http://web.mit.edu/caspar/aerosurvey.htm 